\title{
GAIN ENHANCEMENT AND MINIATURIZATION OF DUAL-BAND COMPACT PATCH ANTENNA
}

\author{
İsa ATAŞ ${ }^{l^{*}}$, Teymuraz ABBASOV ${ }^{2}$, M. Bahaddin KURT ${ }^{3}$
}

\begin{abstract}
In this study, how to increase the dual-band Patch Antenna (PA) gain for the performance improvement of PAs is explained step by step. In addition, a novel method was added for further miniaturization and gain enhancement of the PA. Low cost FR4 substrate was preferred for the design and production of this model. The performance of the proposed antenna was evaluated in terms of Return Loss (RL), surface current distribution, gain and radiation efficiency. For this purpose, HFSS which is a commercial software and that solves electromagnetic structures by finite element method was used in modeling and design steps. The prototype of the produced antenna was measured with a vector network analyzer and the output characteristics were evaluated. The measurement and simulation results of this antenna were found to be consistent and comparable. The peak gain values of the proposed antenna at $5.8 \mathrm{GHz}$ and $10 \mathrm{GHz}$ were obtained as $2.88 \mathrm{dBi}$ and $7.24 \mathrm{dBi}$, respectively.
\end{abstract}

Key words: Dual-band, gain, impedance matching, miniature antenna, patch.

\section{Introduction}

Due to the rapid increase in wireless communication technologies and the demand for multiple frequency applications, compactly structured PAs provide the best solution. These antennas can be integrated with various portable devices for efficient data transmission and reception [1]. PA has many advantages, but it has two main disadvantages as low gain and narrow bandwidth. Various methods are used to overcome these disadvantages. These methods are:

a. Etched Slots on the Patch [2],

b. Appropriate feeding [3],

c. Cutted Substrate Structure (CSS) [4],

d. Adding different shaped parasitic patches to the patch at appropriate positions [5].

Although these methods are used to increase the gain and bandwidth of the antenna in the literature, in our study we have focused on increasing the number of working band and the gain of an antenna by using these methods. There have been numerous designs of multi-band PAs over the past decades, especially for wireless communications, $3.5 \mathrm{GHz}$ WiMAX $(3.3$ - 3.7) $\mathrm{GHz}, 5.5 \mathrm{GHz}$ WLAN (5.150 - 5.825) GHz and $10 \mathrm{GHz}(8-12) \mathrm{GHz}$ radar applications.

\footnotetext{
1 Diyarbakır Vocational School of Technical Sciences, University of Dicle, Diyarbakır, Turkey, (isa_atas@dicle.edu.tr) https://orcid.org/0000-0003-4094-9598

2 Department of Electrical\&Electronics Engineering, University of İnönü, Malatya, Turkey, (teymuraz.abbasov@inonu.edu.tr) https://orcid.org/0000-0002-0290-8333

3 Department of Electrical\&Electronics Engineering, University of Dicle, Diyarbakır, Turkey, (bkurt@dicle.edu.tr) https://orcid.org/0000-0001-6983-2081 
Some of those were planar multiple shaped strips with binomial curved conductor support [6], meander line and a patch in the form of a reverse toothbrush [7], miniaturization of a planar strip shaped monopole antenna for WLAN application [8], DGS with multi-strip monopole antenna [9], Inverted-F Antenna (IFA) structure [10], H-shaped antenna for GPS and Wi-Fi applications [11], microstrip antenna with improvement in performance using DGS [12], extended L-shaped multiband antenna for wireless applications [13]. Most of these designed antennas are physically large. As far as literature studies are concerned, the majority of the techniques used for compact size and multi-band antennas are complicated due to the necessity of additional structures or due to their large size. In order to design a small and compact wireless device, it is necessary to miniaturize the antenna size accordingly.

The ITU (International Telecommunication Union) had originally reserved a portion of the RF spectrum globally for industrial, scientific and medical (ISM) applications. [14] One of the ISM bands, which has center frequency of $5.8 \mathrm{GHz}$ is between $5.725 \mathrm{GHz}$ and $5.875 \mathrm{GHz}$. The frequency band of $5.8 \mathrm{GHz}$ is especially important for high speed Wi-Fi routers, FPV (First Person View) applications where antennas with smaller dimensions and profile are desirable. This allows users to access the microwave spectrum without the need for regulations and restrictions that can be applied elsewhere $[15,16]$. In radar engineering, $\mathrm{X}$-band (8.0 to 12.0$) \mathrm{GHz}$ is used extensively for detection and identification of reflective objects such as vehicle, aircraft, ship, space vehicle, human and natural environment [17].

The higher the frequency, the smaller the antenna dimensions. Since our antenna was designed initially according to $10 \mathrm{GHz}$ and then a second operating frequency was added at a frequency of $5.8 \mathrm{GHz}$, the designed antenna dimensions were smaller than the antenna designed in the $5.8 \mathrm{GHz}$ band. Thus, an antenna operating in the $5.8 \mathrm{GHz}$ band is designed with the small dimensions of $10 \mathrm{GHz}$. Moreover, for further miniaturization and gain enhancement of PA, we propose a new method not used in the literature so far [18]. In addition, as far as we have seen in the literature search, we did not find any antenna that works in both $5.8 \mathrm{GHz}$ and $10 \mathrm{GHz}$ as dual band. As a result, this study proposes a new design approach for gain improvement and miniaturization of PA with dual band operating at $5.8 \mathrm{GHz}$ ISM and $10 \mathrm{GHz}$ X-Band Radar applications.

This article is organized as follows. Section II covers the antenna configuration and design procedure. Simulation and measurement results are discussed in Section III and comparison tables are given in this section. Section IV contains the result of this study.

\section{Design Specifications of Proposed Antenna}

In this section, presents a description of the geometric configuration and basic steps involved in the design of the proposed antenna. At each step, the antenna is analyzed and optimized to provide double band operation. At the last step, formation of slotted and parasitic elemented miniaturized antenna model is completed.

\subsection{Antenna configuration}

The geometrical structure of the antenna is shown in Fig. 1. The proposed antenna was implemented on a FR4 substrate with thickness of $1.57 \mathrm{~mm}$, dielectric constant 4.4 and loss tangent 0.019 , while copper patch having a thickness of $0.035 \mathrm{~mm}$ was used as the radiating element. The prototype of the antenna whose design model has been completed and which has the predicted performance parameter 
has been fabricated out with the printed circuit board. The photograph of the prototype antenna produced is shown in Fig. 2. Detailed dimensions of the recommended antenna are listed in Tab. 1.

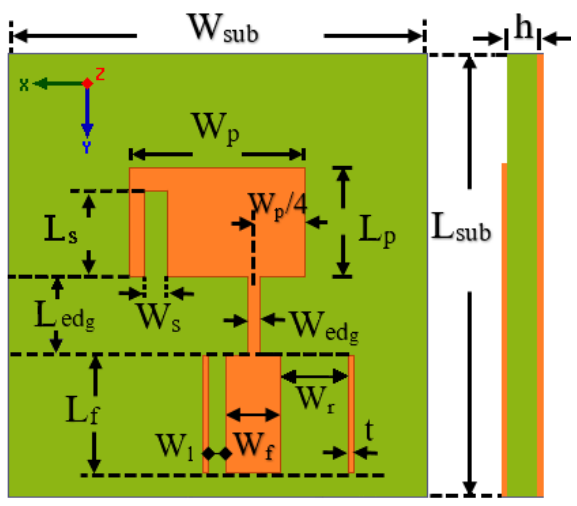

(a)

(b)

Figure 1. Proposed antenna structure: (a) Front view (b) Side view.

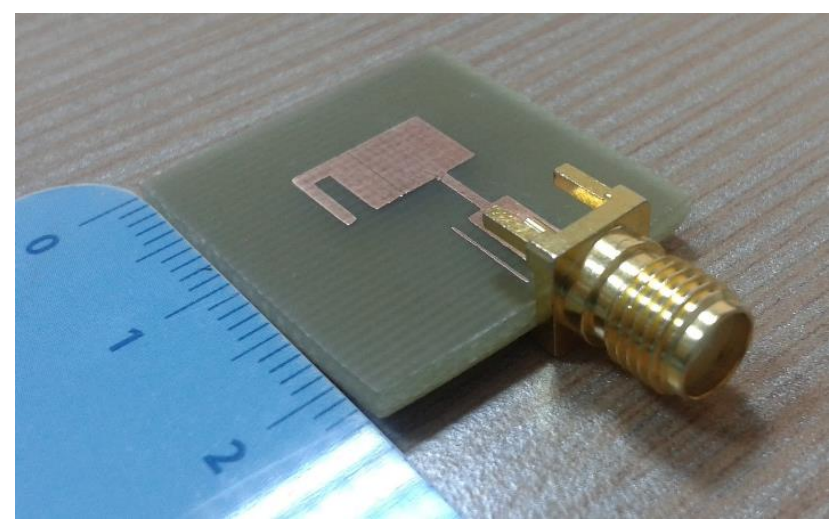

Figure 2. Photograph of fabricated antenna.

Table 1. Dimensions of proposed antenna.

\begin{tabular}{cccc}
\hline Parameter & Value $(\mathbf{m m})$ & Parameter & Value $(\mathbf{m m})$ \\
\hline $\mathrm{L}_{\text {sub }} / \mathrm{Lg}_{\mathrm{g}}$ & 23 & $\mathrm{Ledg}$ & 4.3 \\
$\mathrm{~W}_{\text {sub }} / \mathrm{W}_{\mathrm{g}}$ & 23 & $\mathrm{~W}_{\text {edg }}$ & 0.7 \\
$\mathrm{~L}_{\mathrm{p}}$ & 6.0 & $\mathrm{~L}_{\mathrm{f}}$ & 6.5 \\
$\mathrm{~W}_{\mathrm{p}}$ & 9.6 & $\mathrm{~W}_{\mathrm{f}}$ & 3.0 \\
$\mathrm{~L}_{\mathrm{s}}$ & 4.75 & $\mathrm{~W}_{\mathrm{r}}$ & 3.75 \\
$\mathrm{~W}_{\mathrm{s}}$ & 1.25 & $\mathrm{~W}_{\mathrm{l}}$ & 1.0 \\
$\mathrm{~h}$ & 1.57 & $\mathrm{t}$ & 0.25 \\
\hline
\end{tabular}

\subsection{Antenna configuration}

Initially, even though its loss tangent is relatively high, we preferred the FR4 substrate in our design because of the advantages of being cheap and easy to obtain. The FR4 substrate consists of an epoxy matrix reinforced with woven glass. This composition of epoxy resin and fiber glass varies in thickness and depends on direction [19]. In Antenna\#1, we obtained the initial dimensions of PA with the rectangle patch with edge feed by using Transmission Line Model (TLM) for $10 \mathrm{GHz}$ resonance frequency. To operate in the fundamental mode, the length of the patch must be less than $\lambda g / 2$, where $\lambda g$ is the wavelength in the dielectric medium and is equal to $\lambda o l \sqrt{\varepsilon_{e f f}}$ is the effective relative permittivity which can be obtained by the following Eq. (1) [20]. Where $h, W$ and $\varepsilon_{r}$ are the thickness of substrate, the 
width of microstrip patch and relative permittivity, respectively. The initial antenna was fed from the side by a quarter-wave microstrip line to provide impedance matching.

$$
\varepsilon_{e f f}=\frac{\varepsilon_{r}+1}{2}+\frac{\varepsilon_{r}-1}{2}\left(1+\frac{12 h}{W}\right)^{-1 / 2}
$$

The relationship between resonance length $L_{e d g}$ and directed wavelength $\lambda g$ is given in the Eq. (2) below [21]. Where $c$ refers to speed of light and $f r$ is the resonance frequency.

$$
L_{e d g}=\frac{\lambda_{g}}{4}=\frac{c}{4 f_{r} \sqrt{\varepsilon_{e f f}}}
$$

Since the accuracy of the TLM approach is not very good, the results obtained from the simulation with these TLM values do not provide desired characteristics as much. At this point, adjusting of the patch size is necessary for desired characteristics of antenna. This is done by trial and error method and some simulation programs. In our case, parametric analysis tool of HFSS [22] program was used to obtain right size of the patch which is to be used in the next steps. In all the other steps we used the same HFSS tool for optimum performance as well. In Antenna\#2, slot opening method was used to obtain dual-band characteristic on a standard rectangular antenna. Firstly, we fixed the feed position at the center and opened a slot on the patch and changed the position of it while observing the return loss variation [23]. As a result, a second frequency (changing from $5 \mathrm{GHz}$ to $7 \mathrm{GHz}$ ) appeared with $10 \mathrm{GHz}$. Then, the feeding position has been changed for further improvement of the RL [24]. After then, for the intended dual band of $5.8 \mathrm{GHz}$ and $10 \mathrm{GHz}$ frequencies, good results have been obtained with the use and optimization of these two methods together and the resulting antenna. Also, the effects of the different slot sizes on the return loss of the proposed antenna are shown in the Fig. 3. In Antenna\#3, a new technique was used to cut the normal shaped substrate instead of scratching it. The advantage of the structured substrate is that it helps to reduce the overall size of the antenna by increasing its gain.

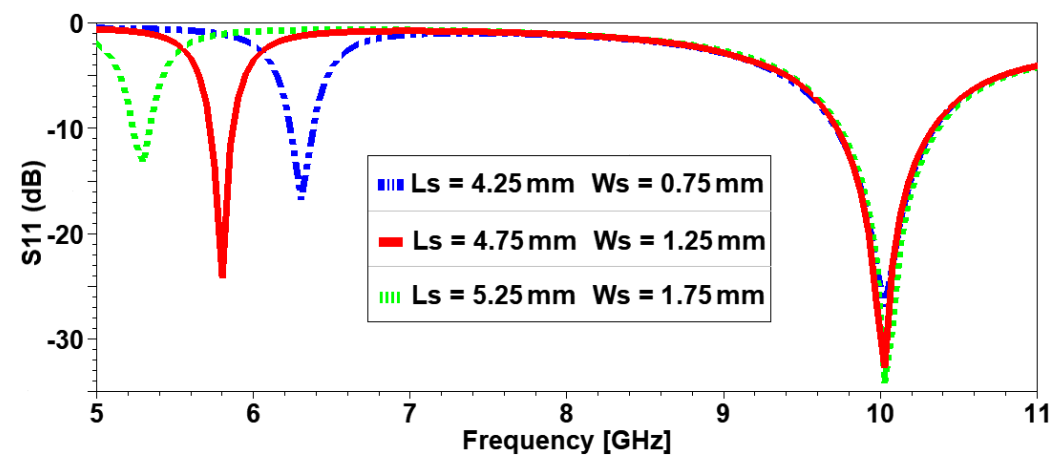

Figure 3. Effect of the size of slots of the proposed antenna.

This method provides an innovation for miniature antenna designs and can be added to the methods used in the literature [18], [25, 26]. In Antenna\#4, for further return loss and gain improvement, parasitic element (PE)s were optimally placed parallel to the right and left of the feed line [27]. The effects of the evolutionary steps on the S11 of the antennas designed with the methods explained in Antenna\#1 to Antenna\#4 used were shown in Fig. 4. Here, since the return loss graphs overlap one another, the return loss change for each antenna is tabulated in the Tab. 2 for a better view of the results. 


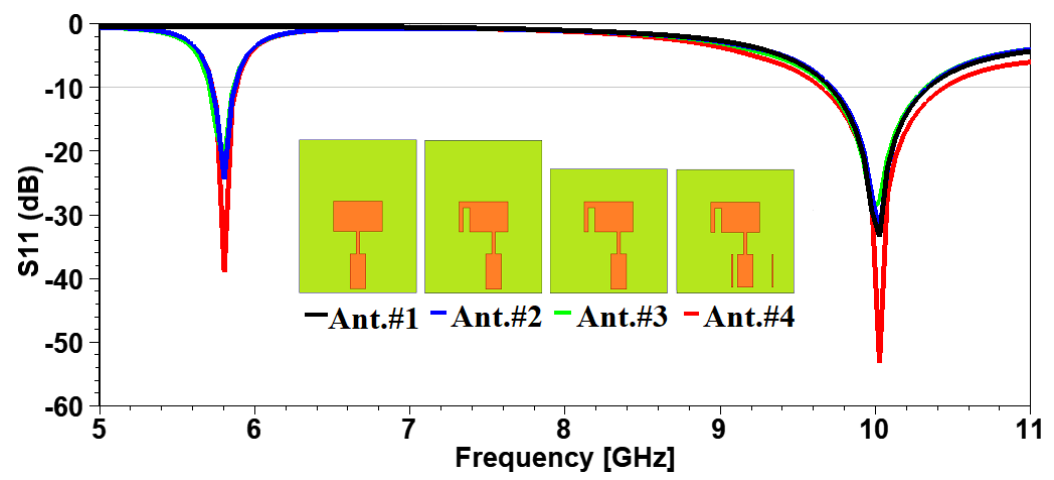

Figure 4. S11 for the Antenna\#1 to Antenna\#4.

Table 2. Comparison of antennas in terms of RL.

\begin{tabular}{ccc}
\hline \multirow{2}{*}{ Type of Antenna } & \multicolumn{2}{c}{$\mathbf{R L} \mathbf{( d B})$} \\
\cline { 2 - 3 } & $\mathbf{5 . 8 ~ G H z}$ & $\mathbf{1 0 ~ G H z}$ \\
\hline Antenna\#1 & - & 34.41 \\
Antenna\#2 & 26.67 & 29.75 \\
Antenna\#3 & 21.45 & 28.36 \\
Antenna\#4 & 38.97 & 53.20 \\
\hline
\end{tabular}

\section{Results and Discussion}

A few of the main performance parameters of an antenna are RL, VSWR, surface current distribution, gain and radiation efficiency. For the proposed antenna, these parameters were simulated and obtained using the HFSS. On the other hand, RL and VSWR measurements were performed using a portable vector network analyzer (ANRITSU MS2028C) covering $10 \mathrm{kHz}-20 \mathrm{GHz}$.

\subsection{Return loss (RL)}

The return loss (negative of the S11) graphics of the proposed antenna at frequencies of $5.8 \mathrm{GHz}$ and $10 \mathrm{GHz}$ are shown in Fig. 5. The results show that close agreements between measured and simulated values are achieved.

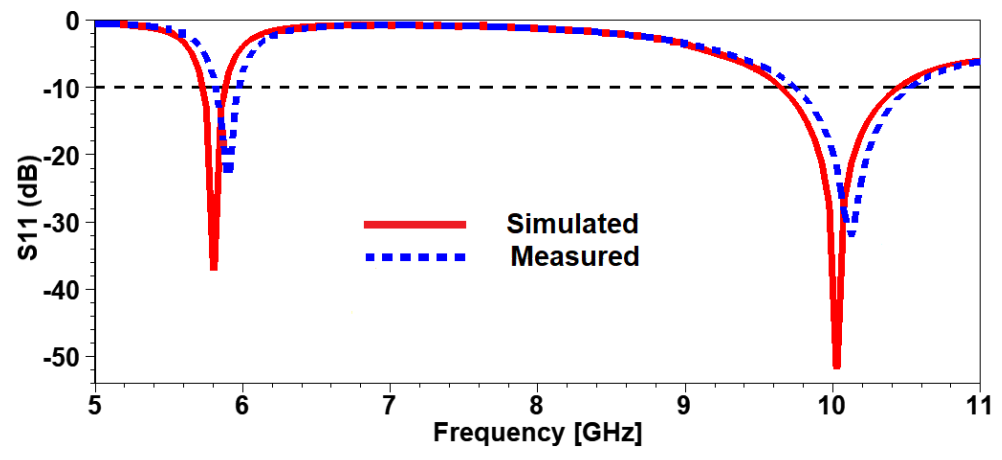

Figure 5. S11 values of the proposed antenna.

There was a slight deviation between the measurement results and the simulation results. This difference can be attributed to the nonconformity in the manufacturing and measurement process. The simulation and measurement results of the prototype antenna are given in Tab. 3. 
Table 3. Dimensions of proposed antenna.

\begin{tabular}{ccccc}
\hline $\begin{array}{c}\text { Proposed } \\
\text { Antenna }\end{array}$ & $\begin{array}{c}\text { Frequency } \\
(\mathbf{G H z})\end{array}$ & $\begin{array}{c}\text { BandWidth } \\
(\mathbf{G H z})\end{array}$ & $\begin{array}{c}\text { Return Loss } \\
(\mathbf{d B})\end{array}$ & VSWR \\
\hline Simulated & 5.80 & $\begin{array}{l}(5.75-5.88) \\
(160) \mathrm{MHz}\end{array}$ & -38.97 & 1.022 \\
& 10.02 & $\begin{array}{c}(9.64-10.44) \\
(800) \mathrm{MHz}\end{array}$ & -53.20 & 1.004 \\
& & & & \\
Measured & 5.95 & $\begin{array}{l}(5.81-5.98) \\
(170) \mathrm{MHz}\end{array}$ & -24.74 & 1.154 \\
& 10.27 & $\begin{array}{c}(9.74-10.52) \\
(780) \mathrm{MHz}\end{array}$ & -32.68 & 1.132 \\
\hline
\end{tabular}

\subsection{Surface current distribution}

The surface current distribution of proposed dual-band miniaturized antenna at 5.8 and $10 \mathrm{GHz}$ is shown in Fig. 6. The surface current distribution at $10 \mathrm{GHz}$ is stronger and more continuous than $5.8 \mathrm{GHz}$, and is also concentrated at patch edges and quarter wave zones.

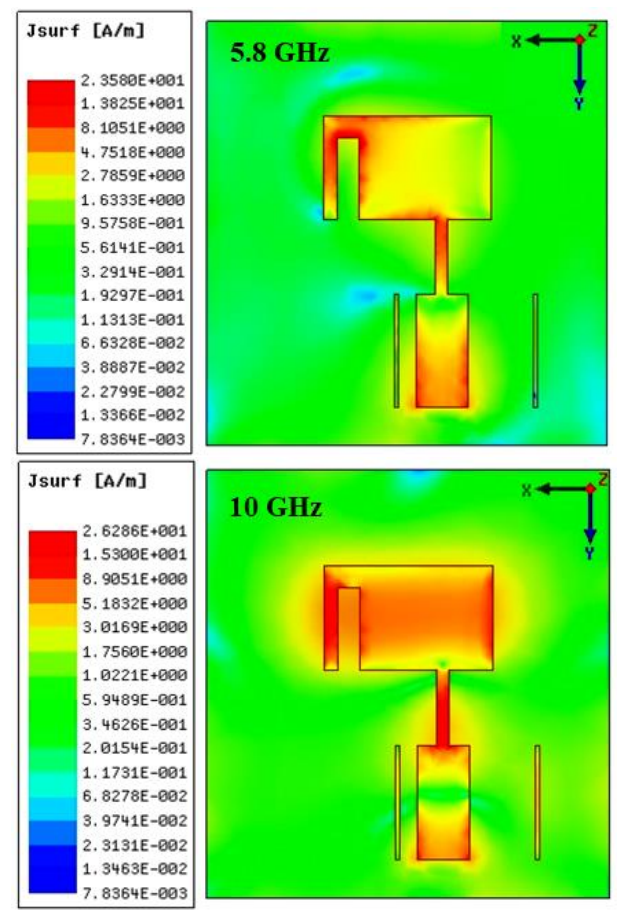

Figure 6. Simulated surface current distributions of antenna: $5.8 \mathrm{GHz}$, and $10 \mathrm{GHz}$.

\subsection{Directivity and gain}

The antennas directivity and gain are relationship to the Eq. (3) given below.

$$
\mathrm{G}_{(\theta, \phi)}=\eta D_{(\theta, \phi)}
$$

Gain is equal to the multiplication of directionality and loss ratio (efficiency) and is expressed in dBi. Here, $\eta$ refers to the radiation efficiency of the antenna and $D$ refers to the directionality of the patch antenna. The angle $\theta$ is the angle in the horizontal plane (azimuth plane) and the angle $\emptyset$ is the angle in the vertical plane (elevation plane) [28]. 
Fig. 7 shows the simulated gain and radiation efficiency of the proposed antenna for frequencies $5.8 \mathrm{GHz}$ and $10 \mathrm{GHz}$. Here, only a few frequencies have been chosen so that the gain and radiation efficiency values are displayed locally. The proposed dual-band miniaturized antenna have provided $2.88 \mathrm{dBi}$ and $7.24 \mathrm{dBi}$ gain, with $49 \%$ and $77 \%$ radiation efficiency at $5.8 \mathrm{GHz}$ and $10 \mathrm{GHz}$ frequencies, respectively.

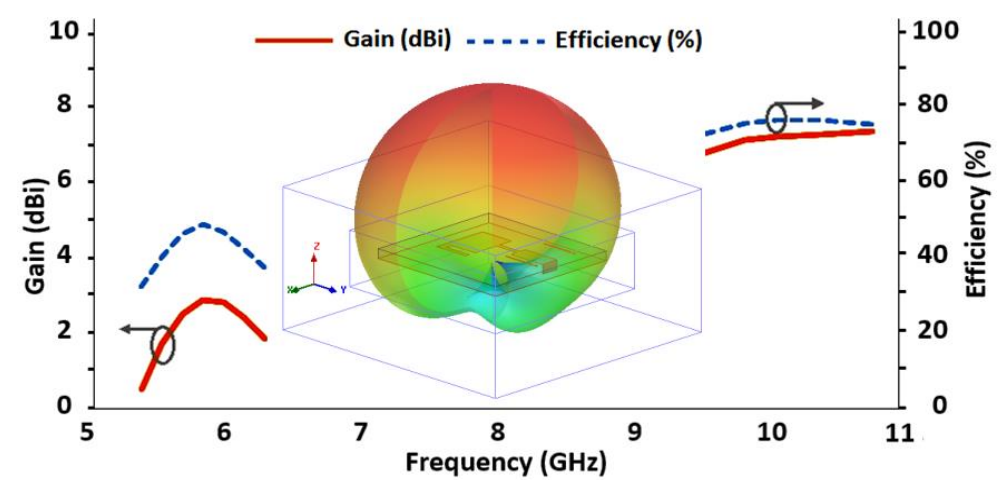

Figure 7. Gain and radiation efficiency of the proposed antenna.

The effects of the evolutionary transformation stages on the antenna gain designed with the methods used are given in Tab. 4. Although the designed antenna is actually small in its own right, it can be considered compact because the dual band capability allows two separate antennas to do its job. Fig. 8 shown comparison of conventional patch antenna and miniature antenna for frequencies $5.8 \mathrm{GHz}$ and $10 \mathrm{GHz}$.

Table 4. Comparison of antennas in terms of the gain.

\begin{tabular}{ccc}
\hline \multirow{2}{*}{ Type of Antenna } & \multicolumn{2}{c}{ Gain (dBi) } \\
\cline { 2 - 3 } & $\mathbf{5 . 8 ~ G H z}$ & $\mathbf{1 0 ~ G H z}$ \\
\hline Antenna\#1 & - & 5.46 \\
Antenna\#2 & 2.59 & 5.84 \\
Antenna\#3 & 2.66 & 7.04 \\
Antenna\#4 & 2.88 & $\mathbf{7 . 2 4}$ \\
\hline
\end{tabular}

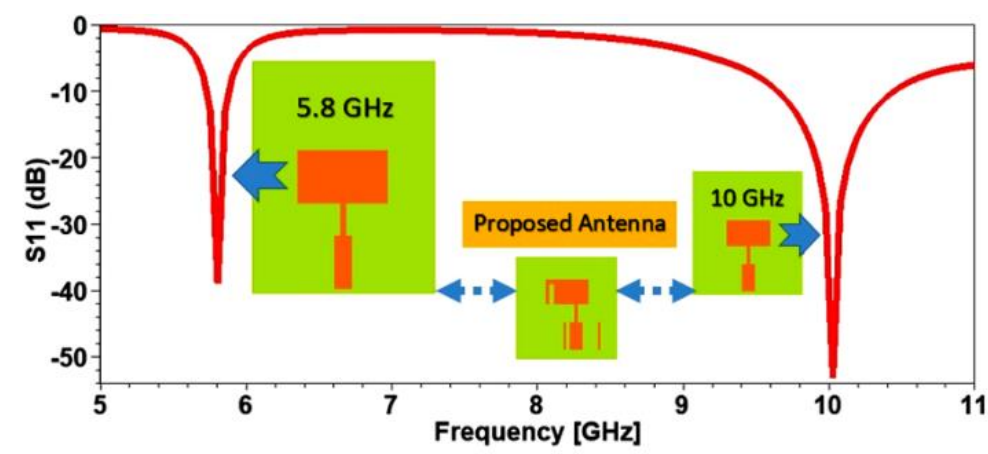

Figure 8. Comparison of conventional patch antennas and miniature antenna for frequencies $5.8 \mathrm{GHz}$ and $10 \mathrm{GHz}$.

The proposed antenna is compared with some recently published studies. In terms of several parameters, the comparison is presented in Tab. 5. 
Table 5. Comparison among other most similar available antennas encountered in the literature.

\begin{tabular}{cccccc}
\hline Referance & No of Band & Area $\left(\mathbf{m m}^{\wedge} \mathbf{2}\right)$ & Height $(\mathbf{m m})$ & Substrate & $\begin{array}{c}\text { Peak Gain } \\
(\mathbf{d B i})\end{array}$ \\
\hline$[12]$ & Dual & 100 & 1 & FR4 & 4.59 \\
{$[17]$} & Dual & 1140 & 1.57 & Rogers & 4.24 \\
{$[29]$} & Dual & 484 & 1.6 & FR4 & 3.44 \\
{$[30]$} & Dual & 900 & 1.6 & FR4 & 5.00 \\
{$[31]$} & Dual & 1270 & 1.6 & FR4 & 5.00 \\
Proposed & Dual & 529 & 1.57 & FR4 & $\mathbf{7 . 2 4}$ \\
\hline
\end{tabular}

\section{Conclusions}

In this study, a dual-band, miniature PA antenna is recommended for ISM and X-band applications. Prototype antenna is compact with overall size $23 \times 23 \times 1.57 \mathrm{~mm}^{\wedge} 3$ with patch dimension $6 \times 9.6$ $\mathrm{mm}^{\wedge} 2$. In order to improve the performance of the proposed antenna, a design approach consisting of four systematic steps was introduced. Parametric analysis was performed to confirm the proposed design and optimize the antenna structure. In the first step, the rectangular slot was opened on the patch to obtain two resonance frequencies $5.8 \mathrm{GHz}$ and $10 \mathrm{GHz}$. It was tried to increase return loss and gain by minimizing the soil area and adding parasitic elements on the antenna. The results were compared in terms of return loss, impedance matching and gain.

\section{Acknowledgment}

The authors would like to thank the "Dicle University Research Projects Committee (DUBAPK)" for the completion of a scientific research under the 14-MF-74 contract.

\section{References}

[1] Wang, H., Zheng, M. (2011). An internal triple-band WLAN antenna. IEEE Antennas and Wireless Propagation Letters, 10, 569-572.

[2] Srilakshmil, A., Koteswararao, N. V., Srinivasarao, D. (2011). X band printed microstrip compact antenna with slots in ground plane and patch. Recent Advances in Intelligent Computational Systems, 851-855.

[3] Tripathi, A. K., Singh, B. K. (2013). A CPW feed X-band antenna for satellite and RADAR application, International Conference on Microwave and Photonics (ICMAP), 1-3.

[4] Sharma, A., Khanna, P., Kumar, A. (2017). A CPW-Fed Structure Shaped Substrate Wideband Microstrip Antenna for Wireless. Journal of Microwaves, Optoelectronics and Electromagnetic Applications, 16(2), 419-443.

[5] Lee, J. H., Yook, J. G. (2010). Improvement of radiation performance of mobile phone antenna using parasitic element. IEEE Transactions on Consumer Electronics, 56(4), 2411-2415. 
[6] Verma, S., Kumar, P. (2015). Compact arc-shaped antenna with binomial curved conductorbacked plane for multiband wireless applications. IET Microwave Antennas Propagation, 9(4), 351-359.

[7] Li, Y., Yu, W. (2015). A miniaturized triple band monopole antenna for WLAN and WiMAX applications. International Journal Antennas Propagation, 1-5.

[8] Fadhel, Y. A., Ataş, M., Abdulhakım, R. M. (2017). Miniaturization of a planar strip shaped monopole antenna for WLAN applications. Journal of University of Duhok, 20(1), 77-89.

[9] Kaur, J., Khanna, R., Kartikeyan, M. (2013). Novel dual-band multistrip monopole antenna with defected ground structure for WLAN BLUETOOTH WIMAX applications. International Journal Microwave Wireless Technology, 6(1), 1-8.

[10] Hirano, T., Takada, J. (2016). Dual band printed inverted F antenna with a nested structure. Progress in Electromagnetic Research Letters, 61, 1-6.

[11] Chang, T. H., Kiang, J. F. (2013). Compact multi-band H-shaped slot antenna. IEEE Transactions on Antennas and Propagation, 61(8), 4345-4349.

[12] Bhadouria, A. S., Kumar, M. (2014). Microstrip X-band antenna with improvement in performance using DGS. Electrical and Electronic Engineering, 31-35.

[13] Ahmad, A., Syeda, F., Naqvi, I., Amin, Y., Tenhunen, H. (2018). Design, fabrication, and measurements of extended L-shaped multiband antenna for wireless applications. Applied Computational Electromagnetics Society Journal (ACES), 33(4), 388-393.

[14] ***,Available Radio Frequency, https://www.everythingrf.com/community/ism-frequencybands

[15] Sharawi, M. S., Khan, M. U., Numan, A. B., Aloi, D. N. (2013). A CSRR loaded MIMO antenna system for ISM band operation. IEEE Transactions on Antennas and Propagation, 61(8), 4265-4274.

[16] Sobhani, M. R., Majidi, N., Imeci, Ş. T. (2018). Design and Implementation of a Quad Element Patch Antenna at $5.8 \mathrm{GHz}$. Applied Computational Electromagnetics Society Journal (ACES), 33(10), 1131-1134.

[17] Datta, B., Das, A., Kundu, A., Chatterjee, S., Mukherjee, M., Chowdhury, S. K. (2013). Twice-band irregular rectangular cut in microstrip patch antenna for microwave communication. International Conference on Information Communication and Embedded System, 598-602.

[18] Khan, M. U., Sharawi, M. S., Mittra, R. (2015). Microstrip patch antenna miniaturization techniques: A Review. IET Microwaves, Antennas \& Propagation, 9(9), 913-922.

[19] Islam, M. T., Samsuzzaman, M. (2014). Miniaturized dual band multi slotted patch antenna on poly tetra fluoroethylene glass microfiber reinforced for $\mathrm{C} / \mathrm{X}$ band applications. Hindawi Publishing Corporation the Scientific World Journal, 1-14.

[20] Balanis, C. A., Antenna Theory, Analysis and Design, John Wiley and Sons Inc., New York, USA, 2005 
[21] Pozar, D. M., Schaubert, D. H., Microstrip Antennas, the Analysis and Design of Microstrip Antennas and Arrays, IEEE Press, New York, USA.1995

[22] High Frequency Structure Simulation (HFSS), v. 15.2, Ansoft ANSYS, 2015.

[23] Elboushi, A., Sebak, A. R. (2014). High gain hybrid DRA / horn antenna for MMW applications. IEEE Antennas and Propagation Society International Symposium (APSURSI), 909-913.

[24] Zhang, H., Zhou, U., Wu, Z., Xin, H., Ziolkowski, R. V. (2010). Designs of ultra wideband (UWB) printed elliptical monopole. Microwave and Optical Technology Letters, 52, 466-471.

[25] Rakholiya, A. A., Langhnoja, N. V. (2017). A review on miniaturization techniques for microstrip patch antenna. International Journal of Advance Research and Innovative Ideas in Education, 3(2), 4281-4287.

[26] Ataş, İ., Kurt, M. B., Abbasov, T. (2019). Development of a High Gain, Double Band and Two Layer Miniaturized Microstrip Antenna for $5.8 \mathrm{GHz}$ ISM and $10 \mathrm{GHz}$ X Band Applications. Applied Computational Electromagnetics Society (ACES), 34(10), 1568-1575.

[27] Zaman, M. R., Islam, M. T., Misran, N., Mandeep, J. S. (2014). Analysis of resonance response performance of $\mathrm{C}$ band antenna using parasitic element. Hindawi Publishing Corporation the Scientific World Journal, 1-10.

[28] Shu, P., Feng, Q. (2013). Design of a compact quad-band hybrid antenna for compass WiMAX WLAN applications. Progress In. Electromagnetics Research, 138, 585-598.

[29] Naji, D. K. (2016). Compact Design of Dual-band Fractal Ring Antenna for WiMAX and WLAN Applications. International Journal of Electromagnetics and Applications, 6(2), 42-50.

[30] Tripathi, S., Saxena, E. R., Kumar, E. M., Jaiswal, A. K. (2018). Performance of microstrip patch antenna for dual band application. International Journal of Engineering and Techniques, 4(1), 193-198.

[31] Jo, S., Choi, H., Shin, B., Oh, S., Lee, J. (2014). A CPW-fed rectangular ring monopole antenna for WLAN applications. International Journal of Antennas and Propagation, 1-6. 